\title{
Cost-benefit trade-offs of bird activity in apple orchards
}

Rebecca K Peisley, Manu E Saunders, Gary W Luck

Birds active in apple orchards in south-eastern Australia can contribute positively (e.g. control crop pests) or negatively (e.g. crop damage) to crop yields. Our study is the first to identify net outcomes of these activities, using six apple orchards, varying in management intensity, in south-eastern Australia as a study system. We also conducted a predation experiment using real and artificial codling moth (Cydia pomonella) larvae (a major pest in apple crops). We found that: 1 ) excluding birds from branches of apple trees resulted in an average of $12.8 \%$ more apples damaged by insects; 2 ) bird damage to apples was low ( $1.9 \%$ of apples); and 3 ) when trading off the potential benefits (biological control) with costs (bird damage to apples), birds provided an overall net benefit to orchard growers. We found that predation of real codling moth larvae was higher than for plasticine larvae, suggesting that plasticine prey models are not useful for inferring actual predation levels. Our study shows how complex ecological interactions between birds and invertebrates affect crop yield in apples, and provides practical strategies for improving the sustainability of orchard systems. 


\section{Cost-benefit trade-offs of bird activity in apple orchards}

2

3 Rebecca K. Peisley ${ }^{1,2^{*}}$, Manu E. Saunders ${ }^{1 * *}$, Gary W. Luck ${ }^{1 * * *}$

4

5 1. Institute for Land Water and Society, Charles Sturt University, PO Box 789, Albury 2640 NSW Australia,

6 Telephone +61260519945

7 2. School of Environmental Sciences, Charles Sturt University, Albury 2640 NSW Australia

8

$9 *$ Corresponding author: rpeisley@csu.edu.au

10 Telephone: +61 260519945

$11 * *$ masaunders@csu.edu.au

$12 * * *$ galuck@csu.edu.au 


\section{Abstract}

27 Birds active in apple orchards in south-eastern Australia can contribute positively (e.g. control crop pests) or negatively (e.g. crop damage) to crop yields. Our study is the first to identify net outcomes of these activities, using six apple orchards, varying in management intensity, in south-eastern Australia as a study system. We also conducted a predation experiment using real and artificial codling moth (Cydia pomonella) larvae (a major pest in apple crops). We found that: 1) excluding birds from branches of apple trees resulted in an average of $12.8 \%$ more apples damaged by insects; 2 ) bird damage to apples was low (1.9\% of apples); and 3 ) when trading off the potential benefits (biological control) with costs (bird damage to apples), birds provided an overall net benefit to orchard growers. We found that predation of real codling moth larvae was higher than for plasticine larvae, suggesting that plasticine prey models are not useful for inferring actual predation levels. Our study shows how complex ecological interactions between birds and invertebrates affect crop yield in apples, and provides practical strategies for improving the sustainability of orchard systems.

\section{Introduction}

Wild animals in agroecosystems interact with crops in complex ways (e.g. direct consumption, pollination, biological control of crop pests, and nutrient cycling) that may reduce, increase or have a benign effect on crop yield (Borkhataria et al. 2012, Klosterman et al. 2013, Klatt et al. 2014). These effects can have a substantial impact on annual production, resulting in significant increases or declines in yield quantities and market values (Losey and Vaughan 2006, Murray et al. 2013). When considering these benefits and costs together, it is clear that trade-offs exist. For example, the beneficial activity of insectivorous birds preying on pest insects in an orchard and reducing insect damage to fruit is traded off against the detrimental activity of the same birds preying on beneficial pollinators resulting in reduced fruit set. Examining the complexities of animal activity within agroecosystems can highlight these trade-offs and allow for calculation of the net outcome (benefits minus costs) of animal activities on production. This has been considerably overlooked in the literature, with very few studies looking at both costs and benefits of animal activity in the same context (Luck 2013, Peisley et al. 2015, Saunders et al. 2016). Birds are commonly found in almost all agroecosystems and their foraging activity often results in significant beneficial or

52 detrimental effects on crop yields, making them an excellent case study of cost-benefit trade-offs of animal activity 53 in crops. 
55 Birds may significantly increase crop yields by predating on pest invertebrates (Mols and Visser 2002, Johnson et al. 56 2010, Karp et al. 2013, Maas et al. 2013, Ndang'ang'a et al. 2013). For example, a study in the Blue Mountains of 57 Jamaica by Kellermann et al. (2008) found that birds reduced coffee berry borer (Hypothenemus hampei) damage by up to $14 \%$, by consuming this major insect pest, which increased the coffee (Coffea spp.) crop market value by as much as US\$105/ha. Similarly, Mols and Visser (2007) found that great tits (Parus major) reduced caterpillar damage to Dutch apple (Malus domestica) orchards by up to 50\% compared to orchards without the bird species.

However, many bird species, including parrots (Bomford and Sinclair 2002) and passerines (Kross et al. 2012), can inflict costs to growers by consuming crops. For example, European blackbirds (Turdus merula) and common starlings (Sturnus vulgaris) can cause severe damage to grape (Vitis spp.) and blueberry (Vaccinium spp.) crops (Avery et al. 1996, Somers and Morris 2002, Kross et al. 2012). Birds can also indirectly impact on crop yields by consuming beneficial insects such as pollinators or natural enemies (e.g. Galeotti and Inglisa 2001).

Previous research found that apple orchards in south-eastern Australia contain a suite of different bird species with the potential to inflict costs and/or provide benefits to fruit production (Luck et al. 2015). Birds can benefit crop yields by consuming apple pests (e.g. codling moth (Cydia pomonella)) and removing unwanted fruit after harvest, thereby reducing disease risk; however, they can also consume and damage fruit before harvest or prey on insects beneficial to apple production (e.g. pollinators). The net outcome of these activities has not yet been considered.

Therefore, the aims of our study were as follows: 1) to determine if excluding birds from branches of apple trees (via netting) in south-eastern Australia resulted in greater insect damage to fruit (indicating that birds may contribute to controlling insect pests) and reduced crop yields; 2) to determine if bird damage to apples on open branches was higher than on netted branches, reducing crop yields; and 3) calculate a net outcome of bird activity, trading off the potential benefits of birds controlling insect pests vs. birds directly consuming fruit. We also conducted an experiment using real and artificial codling moth larvae to gain further insight into what bird species (or insect predators) might be preying on pest invertebrates in the orchards. 


\section{Materials and methods}

83

84

85

86

87

88

89

90

91

92

93

94

95

96

97

98

99

100

101

102

103

104

105

106

107

108

109

Animal ethics

This research was conducted with approval from the Charles Sturt University Animal Care and Ethics Committee (approval number 14/040).

Study sites

Our study was conducted across six apple orchards in three major apple growing regions in Australia: Batlow, southern NSW (average annual rainfall $1283.0 \mathrm{~mm}$, average annual temperature $6.0^{\circ} \mathrm{C}-16.9^{\circ} \mathrm{C}$ (Bureau of Meteorology 2015)), Shepparton, central Victoria (average annual rainfall $506.4 \mathrm{~mm}$, average annual temperature $8.4^{\circ} \mathrm{C}-22.6^{\circ} \mathrm{C}$ degrees (Bureau of Meteorology 2015)) and Harcourt, central Victoria (average annual rainfall 696.9 mm, average annual temperature $7.7^{\circ} \mathrm{C}-19.8^{\circ} \mathrm{C}$ (Bureau of Meteorology 2015)). All orchards differed in their management practices and landscape composition. Therefore, rather than focusing on categorical comparisons that can overlook ecological complexity (e.g. organic vs. conventional; Winqvist et al. 2013), we ranked orchards along a gradient of intensity based on factors that are known to influence bird communities in agricultural landscapes (Bennett and Ford 1997, Benton et al. 2002, Tscharntke et al. 2008, Luck et al. 2013 ). These included (listed in order of importance) proximity of the orchard to unmanaged natural or semi-natural vegetation, the amount of closest continuous unmanaged vegetation, proximity to large farm buildings, and if the orchard used pesticide sprays (Table 1). For example, native vegetation is known to be important for the presence of birds in agroecosystems (Bennett and Ford 1997, Tscharntke et al. 2008); Luck et al. (2013) found that farm buildings were negatively associated with bird abundance in almond orchards (likely owing to the frequency of human activity around buildings); and farms that use pesticides can have lower invertebrate numbers which could in turn reduce the food source available to birds (Benton et al. 2002).

Apple varieties differed across the orchards. These included Pink Lady (Orchard 1, Orchard 4, Orchard 5, Orchard 6), Royal Gala (Orchard 1, Orchard 3), Granny Smith (Orchard 1, Orchard 2, Orchard 4), Golden Delicious 
110 (Orchard 1, Orchard 2), Cox (Orchard 1, Orchard 4), Gravenstein (Orchard 1) and Sundowner (Orchard 4). Tree age

111 also varied across orchards ( $2-20$ years $)$, however all trees were established and producing fruit.

112

113

114

115

116

117

118

119

120

121

122

123

124

125

126

127

128

129

130

131

132

133

134

135

136

137 138

\section{Focal study trees}

Within these orchards, sixty apple trees (ten trees per orchard) were systematically selected to be monitored across the entire season for bird and insect damage. Each tree was spaced at least $15 \mathrm{~m}$ apart; this distance was determined by the size of the smallest orchard (Orchard 1, which was approximately 1 ha). Half of the trees were located near orchard edges adjacent to unmanaged vegetation (established woodland at all orchards except Orchard 6, where an unmanaged grassy meadow was the most proximate area of non-crop vegetation), as this was expected to be a potential source of birds (Tscharntke et al. 2008). The other five trees were located in the centre of the orchard to facilitate a comparison of bird activity (and subsequent costs and benefits) adjacent to and more distant from unmanaged vegetation.

Before flowering (August 2014), two branches of similar height on each tree were selected and marked with flagging tape. One branch was left 'open' under natural conditions and the other was enclosed with white diamond mesh bird netting (15 mm mesh). These 'netted' branches allowed insects to access flowers and fruit while excluding birds. Treatments were paired on each tree to control for differences between trees. The height of the lowest point of the branch, and the distance of each tree to the orchard edge and the nearest patch of unmanaged vegetation was recorded.

\section{Bird surveys}

R.K.P conducted bird surveys between sunrise and 11.00am at four key times of the growing season: full bloom (September 2014), early fruit set (October 2014), pre-harvest (December 2014) and post-harvest (May 2015). At each of these times, the species, abundance and behaviour of birds within the apple orchards and adjacent areas of unmanaged vegetation (except at Orchard 6 where there was no adjacent unmanaged vegetation) were identified. This was to determine what bird species occurred in the vicinity of each orchard. 
139 Timed searches with a pre-determined stopping rule were conducted to identify species richness in orchards and

140 unmanaged vegetation (Miller and Cale 2000, Watson 2003). An active search method was used whereby the

141 observer searched each orchard or unmanaged vegetation patch for 15 minutes and recorded every new bird species

142 observed. If a new species was observed within 5 minutes after the initial 15 minutes had elapsed, an extra 5 minutes

143 was added to the search time. This was repeated until no new species were observed in an additional 5 minute

144 period. Birds that were flying greater than $5 \mathrm{~m}$ above the canopy were excluded, unless they were foraging (e.g.

145 welcome swallows (Hirundo neoxena) hawking insects).

146

147 To gain a measure of bird abundance, five 'points' were chosen within the orchard (Corner 1, Corner 2, Corner 3,

148 Corner 4 and Centre). Observations were started 1 minute after arrival at each point, to allow birds to settle. The

149 identity and abundance of each bird was then recorded for 5 minutes. A short survey period was employed to reduce

150 the risk of double-counting the same individuals (Gregory et al. 2004). The distance to every bird observed was

151 measured to facilitate the calculation of detectability corrected density measures for each species. However, bird

152 abundance (i.e. sample size per species) was not sufficient to allow this calculation, so only general abundance

153 measures are provided in the results.

154

155 The 10 focal trees per orchard were also observed for a maximum of 30 minutes and the identity and activity

156 (particularly foraging behaviour) of every bird that visited was recorded (Supporting methods 1, Supplementary

157 information). Birds were classified into the following feeding groups using the published literature to identify the

158 main component of each species' diet: omnivore, herbivore, insectivore, granivore and carnivore. If a species had

159 two or more main components in its diet (e.g. fruit and insects), then it was classified as an omnivore (del Hoyo et

160 al. 1992-2013).

161

162

Apple damage assessments

163 Immediately before harvest, all apples on both open and netted branches were counted, and the number of any insect

164 or bird damaged apples were recorded. Published damage guides (e.g. Victorian Department of Natural Resources

165 and Environment 2002, Victorian Department of Environment and Primary Industries 2014) and personal

166 observations were used to identify damage type. For example, bird damage is often categorised by triangular beak 
167 marks or deep gouges (Figure S1a+b, Supplementary information) and insect damage usually occurs as circular 168 tunnels or characteristic scar marks (Figure S1c+d, Supplementary information). Damage by both birds and insects

169 was measured to the nearest millimetre at the widest diameter of the mark. Aborted fruit inside nets were not 170 counted, as we could not ascertain how many fruit had been dropped from comparable open branches. The difference in yield between branches was classified as the percentage of fruit on each branch that had damage.

172

173

174 An additional 72 apple trees (12 trees per orchard) were systematically selected to conduct experiments with the 175 primary aims of identifying bird and/or insect predators of pest insects in the orchards, and assessing the validity of 176 using artificial prey analogues to measure predator activity. To our knowledge, no other study has compared predation events on real and artificial prey in the same context at the same time in any crop system (but see Sam et al. 2015 for an example in tropical forests). Each tree was spaced 15 metres apart and was located at orchard edges adjacent to unmanaged vegetation.

Codling moth larvae are a serious insect pest of apples and other pome fruit, with the potential to ruin almost entire fruit crops (Williams 2002). Their natural occurrence in orchards means that they should be an easily recognizable food source for insectivorous birds which prey on invertebrates on the surface of the fruit, foliage or branches of apple trees. This made them an ideal 'model pest' to use to assess which bird species may potentially be providing biological control in apple orchards. Codling moths emerge from over-wintering under the bark of trees in early spring and lay eggs which hatch and infect young fruit. There can be up to three life-cycles in one apple growing season (Williams 2002).

We assessed predation on codling moth larvae using artificial and real moth larvae. Artificial larvae were constructed using plasticine. White and pink plasticine was mixed together and rolled into $1.7 \mathrm{~mm} \times 15 \mathrm{~mm}$ cylinders to create the creamy pink colour and shape of mature coding moth larvae. A $2 \mathrm{~mm}$ diameter ball of black plasticine was also attached to one end as the head (Figure 1). In total, 360 artificial larvae were constructed for this experiment. Studies have shown that using artificial, plasticine larvae can be an effective alternative to real larvae when conducting predation experiments (Koh and Menge 2006, Howe et al. 2009, Tvardikova and Novotny 2012). 
195 They are easier to source and store, and animal damage can often be identified (e.g. insect, bird or mammal).

196 However, few studies have compared predation rates on real vs. artificial prey in the same context to ascertain the

197 usefulness of artificial prey models as analogues of predation rates on real prey (Sam et al. 2015).

198 For real larvae, Agriculture Victoria supplied 360 dormant codling moth larvae (Figure 1). These were killed in the 199 freezer before use to prevent any live larvae from escaping into orchards.

200

201 Half of the artificial and real larvae were stuck individually onto separate $10 \mathrm{~mm}$ x $20 \mathrm{~mm}$ pieces of cardboard using

202 double sided tape (Figure 1), and the other half grouped into 36 groups of 10 (five real and five artificial) and stuck

203 together onto 36, $100 \mathrm{~mm}$ x $200 \mathrm{~mm}$ pieces of cardboard (Figure S2, Supplementary information). Our codling moth

204 larvae likely experienced higher rates of predation than would occur naturally as they were exposed openly on

205 branches and pieces of cardboard; however, our aim here was to determine differences in predation rates between

206 real vs. plasticine baits, rather than infer actual predation rates in orchards.

207 After fruit set (October 2014, coinciding with the fruit set bird surveys), the larvae were set out in the orchard. The

208

209

210

211

212

213

214

215

216

217

218

219

220

growing season was several weeks earlier than usual due to warm weather and codling moth were active throughout the orchards. We also observed codling moth larvae on apple fruit at this time. Ten individual (five real and five plasticine) codling moth larvae were stuck onto branches of six trees in each orchard. Larvae were stuck on branches of similar height, close to apple clusters and easily visible for potential bird predators to find (Figure S2,

Supplementary information). On the remaining six trees, a piece of cardboard containing five real and five artificial larvae was tied to the trunk of the tree or on an adjoining lateral branch (Figure S2, Supplementary information).

These cards were monitored by Reconyx HC500 remote motion sensor cameras to determine which bird species were preying on the larvae. Cameras were set to take a burst of three photos each time they were triggered to enable easy identification of species. Birds most actively forage in the morning so all larvae were set out in the evening to allow for the first morning of bird activity to occur uninterrupted.

\section{Predation surveys}


221 Twenty-four hours after the larvae were exposed every piece of cardboard was checked and larval status was

222 recorded (i.e. present, removed or damaged). Damaged plasticine larvae were inspected further and damage type

223 was identified as either insect or bird ('other', e.g. mammal damage, was also a category based on guides in the

224 literature (Howe et al. 2009); however, only bird and insect damage was encountered). Insect damage was identified

225 with a magnifying glass and occurred as pinpricks and/or pincer marks (Figure S3a,b, Supplementary information).

226 Bird damage was identified by straight beak marks (Figure S3c, Supplementary information). Damage assessments

227 were repeated at the same time every day until larvae had been exposed for 5 days. Other studies using artificial

228 caterpillars had exposure times ranging from 24 hours - 6 days (Loiselie and Farji-Brener 2002, Posa et al. 2007,

229 Howe et al. 2009, Tvardikova and Novotny 2012).

230

231 Statistical analysis

232 Apple damage

233 The response variables for the first experiment were the percentage of apples damaged by birds and the percentage

234 of apples damaged by insects on open and netted branches. However, bird damage was very low (average of $1.9 \% \pm$

$2354.8(95 \%$ confidence interval (CI)), and only detected at two sites (Orchard 1 and Orchard 2), so was not included

236 for analysis.

237 Spearman correlation analysis was used to identify correlated explanatory variables, with only one variable of each

238 correlated pair (correlation defined as $r>0.3$ ) being included in models (see Results). A generalized linear model

239 using a Poisson distribution was fitted using the GENMOD procedure in SAS/STAT (SAS 2011) to determine

240 differences in insect damage to apples between open and netted branches, and whether this difference was

241 influenced by growing Region (Batlow, Shepparton or Harcourt), Orchard (Orchard 1, Orchard 2, Orchard 3,

242 Orchard 4, Orchard 5, or Orchard 6), or Location of the tree in the orchard (edge or interior) (McCullagh and Nelder

243 1989). Since every tree was surveyed twice (one open and one netted branch), a block design using generalized

244 estimating equations was used to account for lack of independence in the data resulting from repeat measures (Liang

245 and Zeger 1986).

246

247 Larvae predation 
248 The response variables for the second experiment were the percentage of plasticine larvae attacked or removed from

249 branches after 5 days, and the percentage of real larvae attacked or removed from branches after 5 days. The

250 explanatory variables were Larvae type (real or plasticine), growing Region (Batlow, Shepparton or Harcourt) and

251 Orchard (Orchard 1, Orchard 2, Orchard 3, Orchard 4, Orchard 5, or Orchard 6). Region was the fixed factor of

252 interest, Orchards were nested within Region, and Larvae type was a repeated measure factor.

253

254 A linear mixed model analysis was performed in SAS/STAT (SAS 2011) fitting the repeated measure, (Larvae type)

255 using an unstructured correlation matrix to determine if: 1) the rate of removal differed between real and artificial

256 larvae; and 2) if there was a relationship between the amount of larvae taken and growing region or orchard.

257

258 Results

259

Apple damage

260

At all sites except Orchard 6 there was more insect damage on netted branches than open branches, with an average

261

of $18.6 \%(95 \%$ confidence interval $(\mathrm{CI})=13.5-25.5 \%)$ of fruit damaged on netted branches and an average of $5.8 \%$

262

$(95 \% \mathrm{CI}=3.9-8.7 \%)$ of fruit damaged on open branches (least squares mean; $\mathrm{p}<0.005)$ (Figure 2). Therefore, the

263

difference in damage between netted and open branches was positive $(12.8 \%, 95 \% \mathrm{CI}=10.8-17.9 \%)$. This suggests

264

that birds were contributing to the biological control of insect pests in most orchards. Orchard 2 had the highest

265

insectivorous bird species richness across the whole season and the greatest average difference in damage between

266

open and netted branches $(21.1 \% \pm 11.9(95 \% \mathrm{CI}))$ (Figure 2). The highest amount of insect damage was also

267

recorded at Orchard 2 with an average of 39.2\% $( \pm 9.2 \%(95 \% \mathrm{CI}))$ of apples on netted branches damaged (Figure

268

S4, Supplementary Information).

269 The distance of an apple tree to unmanaged vegetation was correlated with Orchard $(r=0.452, \mathrm{p}=<0.01)$, and did

270 not greatly improve the QIC value for the model. Orchard was considered a more important variable for capturing

271 other aspects of variation across sites so Distance was excluded. The final explanatory variables selected were as

272 follows: the fixed variables Region (Batlow, Shepparton or Harcourt), Orchard (Orchard 1, Orchard 2, Orchard 3,

273 Orchard 4, Orchard 5 or Orchard 6), and Tree Location (Edge or Interior); and the random variable was an Orchard

$274 \mathrm{x}$ Region interaction term. 
276 The orchard that the tree was in was the only variable that significantly explained the difference in insect damage

277 between netted and open branches $(\mathrm{p}<0.005)$. The difference was greater in the less intensely managed orchards

278 (see ranking scale, Table 1 and Figure S4, Supplementary information), i.e. birds were providing more biological

279 control in these orchards. The region the tree was in (i.e. Shepparton, Harcourt or Batlow) possibly also influenced

280 how much of an effect the exclusion of birds had on insect damage to apples $(p=0.052)$. The greatest difference in

281 damage between netted and open branches occurred in Batlow (average difference of $12.2 \% \pm 7.2(95 \% \mathrm{CI})$ ),

282 followed by Harcourt (average difference of $10.9 \% \pm 8.6(95 \% \mathrm{CI})$ ), and Shepparton (average difference of $6.2 \% \pm$ $28310.7(95 \% \mathrm{CI}))$.

284

285

Insectivorous bird species richness was measured at the orchard level so could not be included in the main analysis,

286 however, when the orchard management intensity was considered against insectivorous bird species richness they

287 were significantly negatively correlated (Spearman $=-0.870, \mathrm{p}<0.05$ ). That is, the least intensively managed

288

289

290

291

292

293

294

295

296

297

298

299

300

301

orchards had the higher insectivore richness (Figure S4, Supplementary information). The average difference in damage between netted and open branches was greater in orchards that had higher insectivore richness (Spearman $=$ $0.841, \mathrm{p}<0.05)$.

\section{Bird species richness}

Overall, 39 different bird species were detected in the six orchards. Thirty-six species were native and three were introduced (Table S1, Supplementary Information). Thirty-four different species were observed during the full bloom period, 19 species were observed during fruit set, 15 species were observed at harvest and 21 species were observed post-harvest. All species observed in the orchards were also observed in adjacent patches of unmanaged vegetation, as well as an additional eight species (Supporting results 1, Supplementary information).

Overall, Orchard 3 had the highest species richness (18), followed by Orchard 1 (16), Orchard 2 and Orchard 4 (15 each), Orchard 5 (12) and Orchard 6 (8) (Figure 3). When species richness was broken down by time of season, Orchard 3 had the highest species richness during the flowering period, with 14 species, followed by Orchard 1 with 12 different species. At fruit set, species richness was also highest at Orchard 3 (9 species), followed by Orchard 2 
302 (7 species) and Orchard 1 (5 species). At harvest time, Orchard 4 had the highest species richness ( 9 species), while 303 at post-harvest species richness was highest at Orchard 2 (8 species).

\section{Feeding guilds}

305

306

307

308

309

310

311

312

313

314

315

316

317

318

319

320

321

322

323

324

325

326

327

Birds were classified by their main feeding type. Omnivores (birds that consumed insects and plant material) were the most common feeding type in all orchards across the entire season, with the exception of Orchard 4 during harvest where there were more insectivorous species. Across the whole season, Orchard 2 had the highest species richness of insectivorous birds (7 species), followed by Orchard 1 (6 species), Orchard 3 and Orchard 4 (5 species each), Orchard 6 (3 species) and Orchard 5 (2 species).

When this was broken down into time of season, four insectivorous bird species were recorded at Orchard 1 and Orchard 3 during flowering, while Orchard 2 and Orchard 6 had three insectivorous species (Figure 7). During early fruiting, only three orchards had predominately insectivorous bird species: Orchard 3 three species, Orchard 2 two species, Orchard 1 one species. At harvest time, Orchard 4 had the highest number of insectivorous species (5) while post-harvest, Orchard 2 had the highest insectivore species richness (5) (Figure S5, Supplementary information).

Larvae predation experiment

Real larvae were preyed on significantly more than plasticine larvae $(p=<0.0001$; Figure 4$)$. There was no clear pattern to this: some orchards with high predation rates on real larvae also had high predation rates on plasticine larvae, however this was not always the case. Region also explained the difference in the predation rate $(\mathrm{p}=<$ 0.001), with the most larvae removed in Batlow, followed by Harcourt and then Shepparton (Figure 4).

Several insectivorous bird species were observed within the orchards during early fruit set and these could potentially be providing biological control of insect pests (Table S1, Supplementary information). However, the motion-sensor cameras only detected two birds (a superb fairy-wren (Malurus cyaneus) and a satin bowerbird (Ptilonorhynchus violaceus)) potentially feeding on the larvae at one orchard (Orchard 3). All predation of plasticine larvae was by insects, with the exception of two bird predated larvae in Orchard 3. The motion-sensor cameras recorded earwigs (Dermaptera sp., including the European earwig (Forficula auricularia)) predating upon the larvae in Orchard 1, Orchard 2 and Orchard 5 (Figure S6, Supplementary information). The damage to larvae in the remaining orchards was similar (pincer marks and 'chewed' sections in the plasticine larvae, and only the hard head 
328 remaining for real larvae) and therefore suggests earwigs or similar predatory invertebrates were also responsible for

329 the majority of predation. Ants (unknown sp.) were also observed eating the real larvae.

\section{The net value of bird activity}

331 Birds damaged an average of $1.9 \%$ of apples within the study orchards, while they reduced the amount of insect

332 damaged apples by an average of $12.8 \%$. This result suggests that birds are providing a net benefit value to orchard

333 growers, reducing damage by an average of $10.9 \%$. When considered at the orchard level, all orchards except two

334 had an overall positive net value of bird activity (Figure 5).

\section{Discussion}

336 This study considered the cost-benefit trade-off between birds providing biological control of insect pests, and bird

337 damage to fruit in apple orchards in central Victoria and southern New South Wales. We found that: 1) excluding

338 birds from branches of apple trees (via netting) resulted in 12.8\% greater insect damage to fruit and reduced crop

339 yields, therefore indicating that birds may contribute to controlling insect pests; 2) bird damage to apples on open

340 branches was very low (1.9\%), and only detected at two sites; and 3) the net outcome of bird activity, trading off the

341 potential benefits of birds controlling insect pests vs. birds directly consuming fruit was positive, with the amount of

342 damaged fruit reduced by $10.9 \%$. The experiment using real and artificial codling moth larvae suggested that

343 earwigs may significantly contribute to the predation of codling moth larvae in apple orchards, and this was more

344 evident in less intense orchards. Real larvae were also predated on more often than plasticine ones. Hence, our

345 combined results suggest that both insectivorous birds and certain predatory insects may together help control insect

346 pests in apple orchards.

347 Apple damage

348 The highest amount of insect damage to apples was recorded at Orchard 2, where almost $40 \%$ of apples on netted

349 branches were damaged. Orchard 6 was the only orchard where trees received less damage on open branches than

350 bird excluded ones, and overall insect damage was low compared with the other orchards. This was possibly due to

351 low species richness of insects (Saunders and Luck, in review) and birds, and relatively substantial pesticide use. It

352 is likely that the lowest intensity orchards (Orchard 1 and Orchard 2), which were certified organic, had more insect 
353 damage because the growers did not spray any pesticides. It is important to note that the damage estimates in the

354 higher intensity orchards reflect the combined influence of natural (biological) and chemical pest control, unlike the 355 two organic orchards which use natural pest control alone.

357 Distance to unmanaged vegetation was not included in the analysis as it was moderately correlated with Orchard,

358 however, native vegetation is important habitat for birds (Bennett and Ford 1997, Tscharntke et al. 2008, Puckett et al. 2009) and this is one possible explanation for why birds were providing greater biological control in the orchards closest to patches of unmanaged vegetation. The least intensively managed orchards had the highest insectivore richness (potential biological control providers), which also supports this conclusion. This was additionally supported by observations during bird surveys, with many insectivorous birds being observed at the orchard edges near unmanaged vegetation (e.g. yellow-faced honeyeaters (Lichenostomus chrysops) and grey fantails (Rhipidura albiscapa) darting to and from unmanaged vegetation and apple trees near the edges of the orchards).

Almost all (92.3\%) of the 39 bird species observed were native. The greatest species richness occurred during the full bloom period, as did the greatest species richness of insectivores (however, these still occurred in fairly high numbers across the whole season). Between early fruiting and harvest, the apple trees in the two Harcourt orchards were covered with drape netting (excluding the open branches used in this experiment) and this appeared to provide a haven for many small bird species (e.g. striated thornbills (Acanthiza lineata) and yellow-faced honeyeaters) which could fit under gaps in the net, while excluding most larger parrot species and birds of prey (e.g. blackshouldered kite (Elanus axillaris).

373

Across the season (flowering, early fruiting and harvest) parrot species (crimson rosella (Platycercus elegans) and eastern rosella (Platycercus eximius)) were observed feeding on flower buds and fruit on the trees (possibly reducing fruit set) in all orchards except for the two in Shepparton (where no parrots were observed). These species were also observed consuming unharvested (waste) fruit on the trees and ground post-harvest, possibly reducing the spread of disease and increasing the transfer of nutrients and organic matter into the soil, which is particularly important in 
381 (beneficial activity) in the same orchard during the early fruiting stage. Therefore, these bird species have the 382 potential to be providing both costs and benefits to growers depending on the time of season. This supports work 383 done by Luck (2013), who found that parrot species in almond orchards caused costs by eating the growing nuts 384 before harvest, but then also provided benefits by cleaning up waste nuts after harvest.

385 The omnivorous silvereye (Zosterops lateralis) was observed eating nectar during flowering (possible detrimental 386 activity of nectar robbery and possible beneficial activity of incidental pollination), gleaning insects from apple

387 leaves and fruit across the whole season (potential beneficial activity of biological control), and eating unharvested

388 or fallen fruit after harvest (potential beneficial activity of reducing the spread of disease and increasing the transfer 389 of nutrients and organic matter into the soil). Such behaviour demonstrates the complex relationships between 390 species activity and crop production, underscoring the importance of accounting for both the costs and benefits of

391 the activity of multiple species across the entire growing season for individual crops in different contexts (see

392 Saunders et al. 2016). Other omnivorous species, such as the Australian magpie (Cracticus tibicen) and European

393 blackbird, were also identified in the orchards across the whole season and were only observed eating insects, some

394 of which may have been apple pests.

395

396

398

400

401

402

403

404

405

406

407

\section{Larvae predation experiment}

The larvae predation experiment found a significant difference in the prey type used, i.e. real larvae were preyed on more than plasticine larvae. This can possibly be explained by the high incidence of insect predation of larvae, particularly by earwigs. The larvae in this study were first attached to the study trees in the evening to allow birds to have the first morning of foraging uninterrupted (i.e. when they are most active), however many of the real larvae were eaten by earwigs in the first night. This could have reduced the amount of larvae available for birds to prey on that first morning and therefore underestimated their biological control potential. Perhaps more importantly, earwigs seem to be largely overlooked as potential biological control providers of invertebrate pests in apple orchards.

European earwigs are known to cause damage to many crop types (Capinera 2001), although they have also been shown to provide benefits such as controlling aphids (e.g. Nicholas et al. 2005, Romeu-Dalmau et al. 2012). Native carnivorous earwigs (e.g. Labidura truncata) are better recognised as potential predators (Williams 2002, Atlas of Living Australia 2015), but more research is needed into their potential as biological control agents, particularly in apple orchards. 
408 Our study found that the use of plasticine larvae significantly under-estimates the amount of predation occurring in

409 the orchard (i.e. they were attacked less than the real larvae). Other studies have found plasticine larvae to be

410 effective in recording predation events (e.g. Loiselie and Farji-Brener 2002, Koh and Menge 2006, Posa et al. 2007,

411 Howe et al. 2009, Tvardikova and Novotny 2012), however these studies did not directly compare their results with

412 predation rates on real larvae. Sam et al. (2015) considered this difference in prey type in a tropical forest system.

413 They found no difference between real and artificial larvae, however they found a significant difference in predation

414 rates based on the type of artificial material used. Our study is therefore the first to consider the differences in

415 predation rates on different types of prey items in fruit orchards. We suggest that while the use of plasticine prey

416 models can help identify potential predators, and they may have some utility in recording differences in relative

417 predation pressure among sites, they should not be used to infer actual predation levels on a given prey type. Our

418 study also suggests that caution should be taken when using plasticine larvae to infer relative predation pressure. For

419 this to be reliable, sites with high predation pressure for real larvae should also have high predation pressure for

420 artificial larvae; however, this was not always the case in our study region.

421 Our study did not consider the potential for insectivorous bats to be providing biological control, although they can

422 be important predators of crop insect pests (Cleveland et al. 2006, López-Hoffman et al. 2014, Wanger et al. 2014,

423 Brown et al. 2015). No bats were recorded on the motion sensor cameras, but several growers have observed

424 insectivorous bats in their orchards, so this would be an important avenue for further investigation. Similarly, some

425 growers commented on grey-headed flying foxes (Pteropus poliocephalus) causing serious damage to apple trees

426 and fruit, but they were not observed during my study and there was no evidence of their damage (e.g. snapped

427 branches and chewed fruit) (Victorian Department of Natural Resources and Environment 2002).

The net value of bird activity

429 When trading off the amount of bird damage in the orchards (average of $1.9 \%$ of apples) with the amount of 430 biological control they provided (i.e. reducing apples damaged by insects by $12.8 \%$ ), it can be suggested that birds

431 are providing an overall net benefit to orchard growers, reducing damage by an average of $10.9 \%$. This value

432 differed between orchards, with birds providing less biological control in the most intensively managed orchard

433 (Orchard 6), and also causing more damage to apples than the insect control they provided in the least intensively

434 managed orchard (Orchard 1) (i.e. a net outcome that was detrimental to growers). This highlights the importance of 
435 recognizing the spatio-temporal, management and ecological differences between orchards and understanding that

436 there is no one-size-fits-all approach to sustainable management. Bird damage was only detected at two sites,

437 Orchard 1 and Orchard 2, which were the two least intensely managed orchards. As insectivore species richness

438 was also highest in these orchards, this suggests that there is a point when the trade-off between encouraging

439 insectivores (e.g. by planting native vegetation near orchards) may be out-weighed by attracting detrimental species

440 (e.g. parrots). Though data are sparse, my results suggest that some active management of apple orchards is required

441 to tip the balance in favour of a positive net outcome of bird activity for growers.

442 It is important to note that the bird damage recorded in my study was low and likely impacted by orchard

443 management actions (e.g. drape netting). While some studies suggest that bird damage to apples is also low (e.g.

444 Long (1985) who found a maximum of 1.75\% damaged fruit per orchard), other studies have found bird damage in

445 apples to be much higher, for example up to 18\% in some varieties (Grasswitz and Fimbres 2013). These studies

446 also found that the amount of damage depended on apple variety, with birds showing a preference for red-coloured,

447 late season ripening fruit. Logistical reasons prevented us from controlling for apple variety, so all apple damage

448 assessments were done at the same time in the season to account for temporal variation in bird activity. However, it

449 is possible that apple variety could have impacted damage levels across orchards.

450 The amount of bird damage to crops can also vary between seasons and years (e.g. Long 1985, Luck et al. 2013). In

451 addition, there is a large amount of spatial variability in damage from large flocks of birds (e.g. cockatoo species)

452 that descend somewhat randomly on localised areas in orchards (Long 1985). Therefore, it is possible that at other

453 sites within the study orchards, or in future years, there may be more apple damage by birds. This is supported by

454 personal observations of crimson rosellas and Australian king parrots (Alisterus scapularis) feeding on uncovered

455 fruit near orchard edges at four of the orchards, and growers' observations of flocks of musk lorikeets (Glossopsitta

456 concinna) feeding on fruit in previous years. Therefore, further work is needed to consider the cost-benefit trade-off

457 of bird activity over larger spatial scales and longer time spans.

458 Our study begins to address the complex ecological interactions that occur between birds, invertebrates and apple 459 crops. It highlights how birds can provide costs or benefits to growers depending on a range of contextual factors 460 including time of season, location, and interactions with other fauna (i.e. invertebrates). This can better inform land 461 managers about implementing strategies which promote the beneficial processes that are essential to the 
462 sustainability of agriculture and conservation alike (Saunders et al. 2015, Peisley et al. 2015), while reducing

463 negative impacts on production.

464

465

\section{Acknowledgements}

466

467

468

469

470

471

472

473

474

475

476

477

478

479

480

481

482

483

484

485

486

487
Many thanks to W. Robinson at Charles Sturt University for assistance with the statistical analysis; D. Williams and M. Hossain at Agriculture Victoria for providing the live codling moth larvae; and A. Peisley and two anonymous reviewers for comments on the manuscript.

\section{References}

1. Avery ML, Primus TM, Defrancesco J, Cummings JL, Decker DG, Humphrey JS, Davis, JE and Deacon, R (1996) Field Evaluation of Methyl Anthranilate for Deterring Birds Eating Blueberries. The Journal of Wildlife Management, 60:929-934.

2. Atlas of living Australia (2015) Labidura truncate URL: http://bie.ala.org.au/species/urn:lsid:biodiversity.org.au:afd.taxon:fc776017-093a-4e1e-abe5-25d62d43de06.

3. Australian Bureau of Meteorology (2015) Climate Data Online. URL: http://www.bom.gov.au/climate/data/index.shtml.

4. Bennett AF and Ford LA (1997) Land use, habitat change and the conservation of birds in fragmented rural environments: a landscape perspective from the Northern Plains, Victoria, Australia. Pacific Conservation Biology, 3:244 - 261 .

5. Benton TG, Bryant DM, Cole L and Crick HQP (2002) Linking agricultural practice to insect and bird populations: a historical study over three decades. Journal of Applied Ecology, 39:673-687.

6. Borkhataria RR, Nuessly GS, Pearlstine E, Cherry RH (2012) Effects of blackbirds (Agelaius phoenicius) on stink bug (Hemiptera: Pentatomidae) populations, damage, and yield in Florida rice. Florida Entomologist, 95:143-149.

7. Brown VA, Braun de Torrez E and McCracken GF (2015) Crop pests eaten by bats in organic pecan orchards. Crop Protection 67: 66-71. 
8. Capinera J (2001). Handbook of vegetable pests. Gulf Professional Publishing.

489

9. Cleveland CJ, Betke M, Federico P, Frank JD, Hallam TG, Horn J, López Jr JD, McCracken GF, Medellín RA, Moreno-Valdez A, Sansone CG, Westbrook JK and Kunz TH (2006). Economic value of the pest control service provided by Brazilian free-tailed bats in south-central Texas. Frontiers in Ecology and the Environment, 4:238-243.

10. Del Hoyo J, Elliot A, Sargatal J, Christie DA, eds (1992-2013) Handbook of the birds of the world. Volumes 1,2,4,6,9-15. Lynx Edicions, Barcelona.

11. Galeotti P, Inglisa M (2001) Estimating predation impact on honeybees Apis mellifera L. by European beeeaters Merops apiaster L. Revue d'Écologie 56:373-388.

12. Grasswitz TR and Fimbres O (2013) Efficacy of a physical method for control of direct pests of apples and peaches. Journal of Applied Entomology, 137:790-800.

13. Gregory RD, Gibbons DW and Donald PF (2004). Bird census and survey techniques. Bird ecology and conservation, 17-56.

14. Howe A, Lövei GL and Nachman G (2009) Dummy caterpillars as a simple method to assess predation rates on invertebrates in a tropical agroecosystem. Entomologia Experimentalis et Applicata 131: 325-329.

15. Johnson MD, Kellermann JL and Stercho AM (2010) Pest reduction services by birds in shade and sun coffee in Jamaica. Animal Conservation, 13:140-147.

16. Karp DS, Mendenhall CD, Sandi RF, Chaumont N, Ehrlich PR, Hadly EA, Daily GC (2013) Forest bolsters bird abundance, pest control and coffee yield. Ecology Letters, 16:1339-1347.

17. Kellermann JL, Johnson MD, Stercho AM, Hackett SC (2008) Ecological and economic services provided by birds on Jamaican Blue Mountain coffee farms. Conservation Biology, 22:1177-1185.

18. Klatt BK, Holzschuh A, Westphal C, Clough Y, Smit I, Pawelzik E, Tscharntke T (2014) Bee pollination improves crop quality, shelf life and commercial value. Proceedings of the Royal Society B, 281:2013-2440.

19. Klosterman ME, Linz GM, Slowik AA, Homan, HJ (2013) Comparisons between blackbird damage to corn and sunflower in North Dakota. Crop Protection, 53:1-5.

20. Koh LP and Menge DNL (2006) Rapid Assessment of Lepidoptera Predation Rates in Neotropical Forest Fragments. Biotropica, 38:132-134. 
515 21. Kross SM, Tylianakis JM and Nelson XJ (2012) Effects of introducing threatened falcons into vineyards on abundance of passeriformes and bird damage to grapes. Conservation Biology 26:142-149.

517

518

519

520

521

522

523

524

22. Liang KY and Zeger SL (1986) Longitudinal Data Analysis Using Generalized Linear Models. Biometrika, 73:13-22.

23. Loiselie BA and Farji-Brener AG (2002) What's Up? An experimental comparison of predation levels between canopy and understory in a tropical wet forest. Biotropica, 34:327-330.

24. Long JL (1985) Damage to Cultivated Fruit by Parrots in the South of Western Australia. Aust. Wildl. Res., 12:75-80.

25. López-Hoffman L, Wiederholt R, Sansone C, Bagstad KJ, Cryan P, Diffendorfer JE, Goldstein J, LaSharr K, Loomis J, McCracken G, Medellín RA, Russell A and Semmens D (2014) Market Forces and Technological Substitutes Cause Fluctuations in the Value of Bat Pest-Control Services for Cotton. PLoS ONE 9:e87912.

26. Losey JE, Vaughan M (2006) The economic value of ecological services provided by insects. Bioscience, 56:311-323.

27. Luck GW, Hunt K and Carter A (2015) The species and functional diversity of birds in almond orchards, apple orchards, vineyards and eucalypt woodlots. Emu, 115:99-109.

28. Luck GW, Triplett S and Spooner PG (2013) Bird use of almond plantations: implications for conservation and production. Wildlife Research, 40:523-535.

29. McCullagh P and Nelder JA (1989) Generalized Linear Models, Second Edition, London: Chapman \& Hall.

30. Miller JR and Cale P (2000) Behavioral mechanisms and habitat use by birds in a fragmented agricultural landscape. Ecological Applications, 10:1732-48.

31. Mols CMM and Visser ME (2002) Great tits can reduce caterpillar damage in apple orchards Journal of Applied Ecology, 39:888-899.

32. Mols CMM and Visser ME (2007) Great tits (Parus major) reduce caterpillar damage in commercial apple orchards. PLoS One, 2:e202.

33. Murray DAH, Clarke MB and Ronning DA (2013). Estimating invertebrate pest losses in six major Australian grain crops. Australian Journal of Entomology, 52:227-241. 
542 34. Ndang'ang'a PK, Njoroge JBM and Vickery J (2013) Quantifying the contribution of birds to the control of

543 arthropod pests on kale, Brassica oleracea acephala, a key crop in East African highland farmland.

544 International Journal of Pest Management 59:211-216.

545 35. Neeson R (2008) Organic fruit production. New South Wales Department of Primary Industries. URL:

546 http://www.dpi.nsw.gov.au/_data/assets/pdf_file/0020/237800/organic-fruit-production.pdf

547 36. Nicholas AH, Spooner-Hart RN and Vickers RA (2005) Abundance and natural control of the woolly aphid

548 Eriosoma lanigerum in an Australian apple orchard IPM program. BioControl, 50:271-291.

549 37. Peisley RK, Saunders ME and Luck GW (2015) A systematic review of the benefits and costs of bird and insect $550 \quad$ activity in agroecosystems. Springer Science Reviews, 3:113-125.

551 38. Posa MRC, Sodhi NS, and Koh LP (2007) Predation on artificial nests and caterpillar models across a

552 disturbance gradient in Subic Bay, Philippines. Journal of Tropical Ecology, 23:27-33.

553 39. Puckett HL, Brandle JR, Johnson RJ and Blankenship EE (2009) Avian foraging patterns in crop field edges 554 adjacent to woody habitat. Agriculture, Ecosystems and Environment, 131:9-15.

555 40. Queensland Government, Department of Agriculture and Fisheries (2015) Apple disease and pest descriptions.

556 URL: https://www.daf.qld.gov.au/plants/fruit-and-vegetables/fruit-and-nuts/apples/apple-disease-and-pest-

557 descriptions

558 41. Romeu-Dalmau C, Piñol J and Espadaler X (2012) Friend or foe? The role of earwigs in a Mediterranean 559 organic citrus orchard. Biological Control, 63:143-149.

560 42. Sam K, Remmel T and Molleman F (2015) Material affects attack rates on dummy caterpillars in tropical forest 561 where arthropod predators dominate: an experiment using clay and dough dummies with green colourants on various plant species. Entomollogia, DOI: 10.1111/eea.12367.

563 43. SAS Institute Inc. 2011. SAS/STAT® 9.3 User’s Guide. Cary, NC: SAS Institute Inc.

564 44. Saunders ME, Peisley RK, Rader R and Luck G (2016) Pollinators, pests and predators: Recognizing ecological 565 trade-offs in agroecosystems. Ambio, 45: 4-14.

566 45. Somers CM and Morris RD (2002) Birds and wine grapes: foraging activity causes small-scale damage patterns 567 in single vineyards. Journal of Applied Ecology, 39:511-523.

568 46. Thomas Cherico Wanger TC, Darras K, Bumrungsri S, Tscharntke T, Klein A-M (2014) Bat pest control 569 contributes to food security in Thailand. Biological Conservation, 171:220-223. 
570 47. Tscharntke T, Sekercioglu CH, Dietsch TV, Sodhi NS, Hoehn P and Tylianakis JM (2008) Landscape

571 constraints on functional diversity of birds and insects in tropical agroecosystems. Ecology, 89:944-951.

572 48. Tvardikova K and Novotny V (2012) Predation on exposed and leaf-rolling artificial caterpillars in tropical 573 forests of Papua New Guine. Journal of Tropical Ecology, 28:331-341.

574 49. Victorian Department of Environment and Primary Industries (2014) Pest insects and mites URL:

575 http://www.depi.vic.gov.au/agriculture-and-food/pests-diseases-and-weeds/pest-insects-and-mites

576 50. Victorian Department of Natural Resources and Environment (2002) Bird and flying-fox damage to orchard 577 fruit: an identification guide. Melbourne, Victoria.

578 51. Watson DM (2003) The 'standardized search': an improved way to conduct bird surveys. Austral Ecology, $579 \quad 28: 515-25$.

580 52. Williams D (2002) Codling moth general information. Department of Primary Industries, Victoria. URL: http://www.depi.vic.gov.au/agriculture-and-food/pests-diseases-and-weeds/pest-insects-and-mites/codlingmoth.

583 53. Winqvist C, Ahnstro $\mathrm{m} \mathrm{J}$ and Bengtsson J (2012) Effects of organic farming on biodiversity and ecosystem services: taking landscape complexity into account. Annals of the New York Academy of Science, 1249:191203.

586 
596 Table 1. Orchards were classified along a gradient of intensity based on factors that are known to influence

597 bird communities. Distance of study area to unmanaged vegetation was considered the most important intensity

598 factor, followed by distance of the study area to farm buildings, and whether pesticide sprays were used.

\begin{tabular}{|l|l|l|l|l|l|}
\hline $\begin{array}{l}\text { Intensity } \\
\text { ranking }\end{array}$ & Orchard & $\begin{array}{l}\text { Minimum distance } \\
\text { to unmanaged } \\
\text { vegetation }\end{array}$ & $\begin{array}{l}\text { Amount of closest } \\
\text { continuous unmanaged } \\
\text { vegetation }\end{array}$ & $\begin{array}{l}\text { Minimum distance } \\
\text { to farm buildings }\end{array}$ & Pesticide spray \\
\hline 1 & Orchard 1 & $0 \mathrm{~m}$ & $>40 \mathrm{ha}$ & $\sim 100 \mathrm{~m}$ & No \\
\hline 2 & Orchard 2 & $<10 \mathrm{~m}$ & $>1 \mathrm{ha}$ & $\sim 550 \mathrm{~m}$ & No \\
\hline 3 & Orchard 3 & $0 \mathrm{~m}$ & $<2 \mathrm{ha}$ & $\sim 200 \mathrm{~m}$ & Yes \\
\hline 4 & Orchard 4 & $\sim 5 \mathrm{~m}$ & $>15 \mathrm{ha}$ & $\sim 10 \mathrm{~m}$ & Yes \\
\hline 5 & Orchard 5 & $\sim 50 \mathrm{~m}$ & $<0.5 \mathrm{ha}$ & $\sim 250 \mathrm{~m}$ & Yes \\
\hline 6 & Orchard 6 & $>280 \mathrm{~m}$ & & Yes \\
\hline
\end{tabular}

599

600

601

602

603

604

605

606

607

608

609

610 


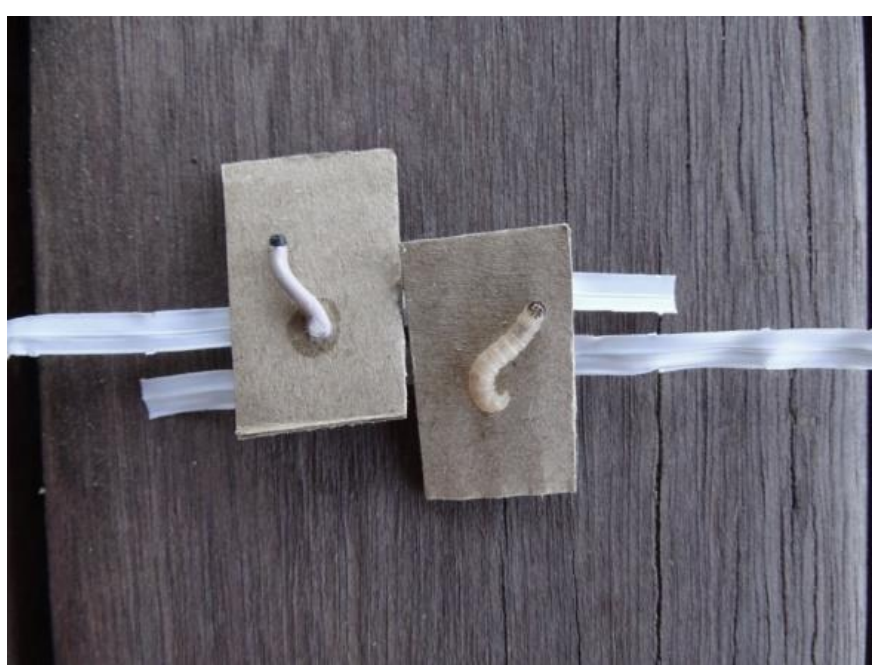

611

Figure 1. Left: plasticine larvae, right: real codling moth larvae.

613

614

615

616

617

618

619

620 


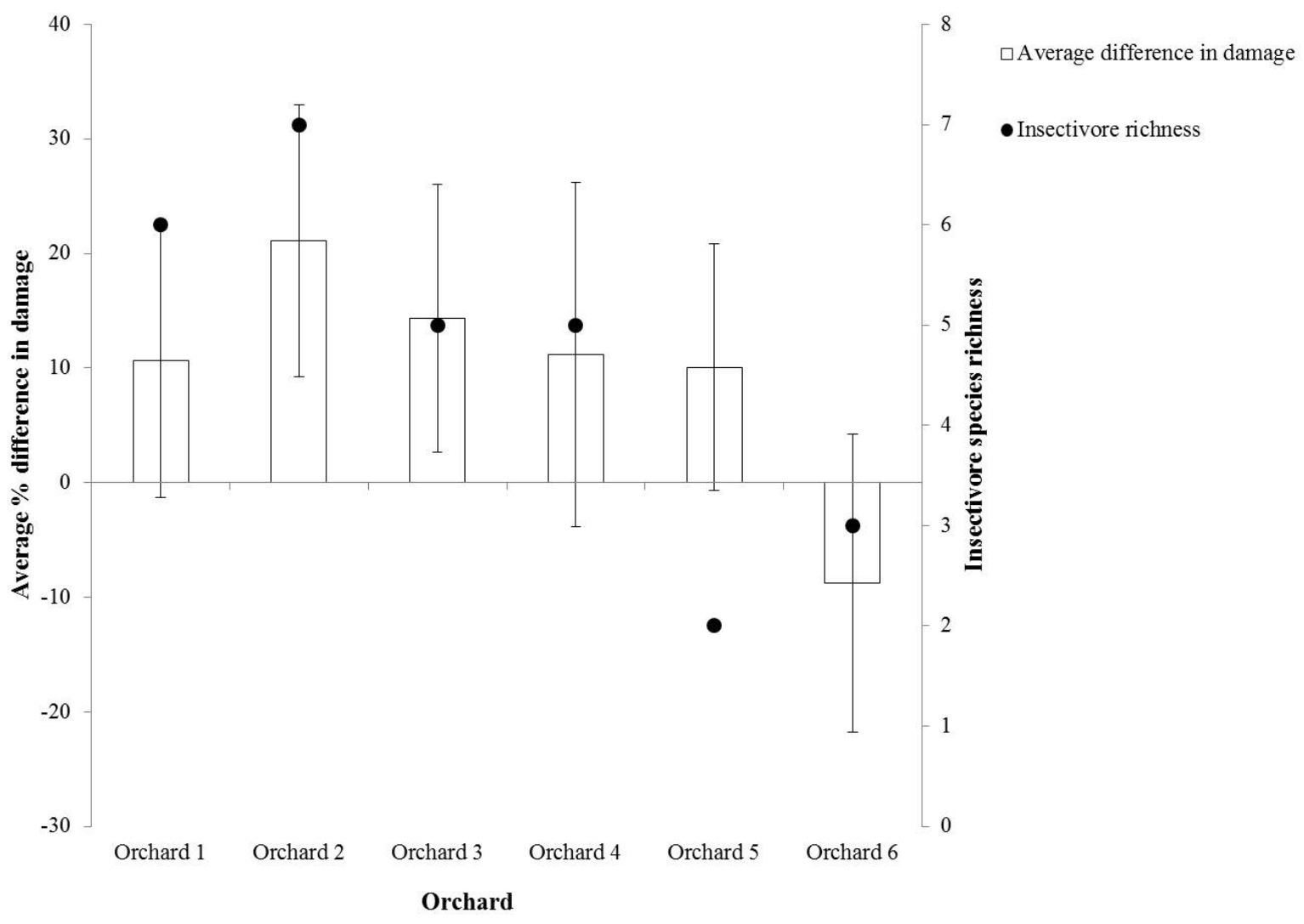

Figure 2. Average difference in \% of insect damaged apples between open and netted branches, compared with insectivorous bird species richness ( $\mathrm{n}=120$ branches). All orchards except Orchard 6 received more insect damage on netted (bird excluded) branches (Error bars show 95\% CI). Orchards are listed 1-6 from lowest intensity management to highest intensity. 


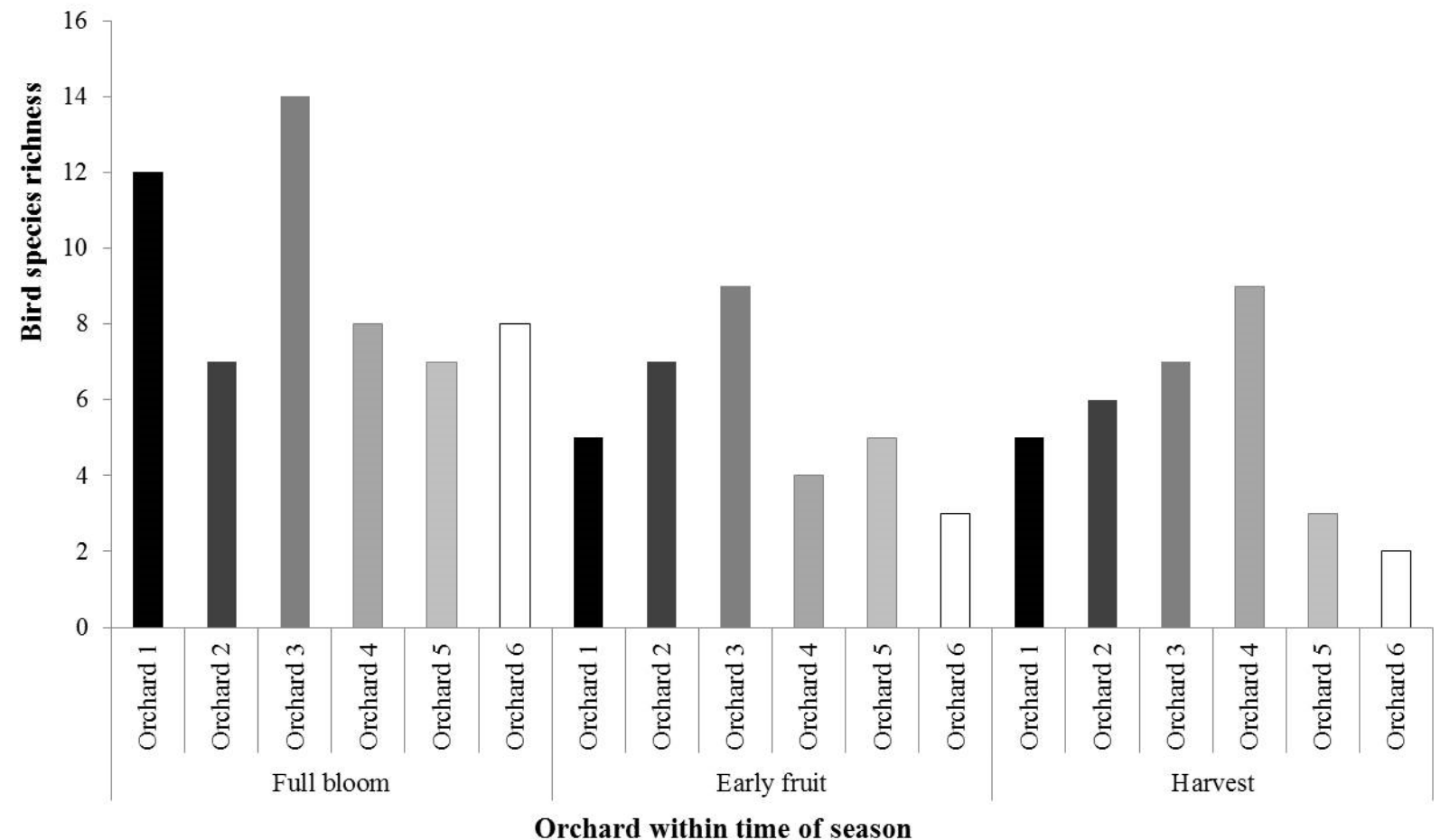

626

627

628

629 


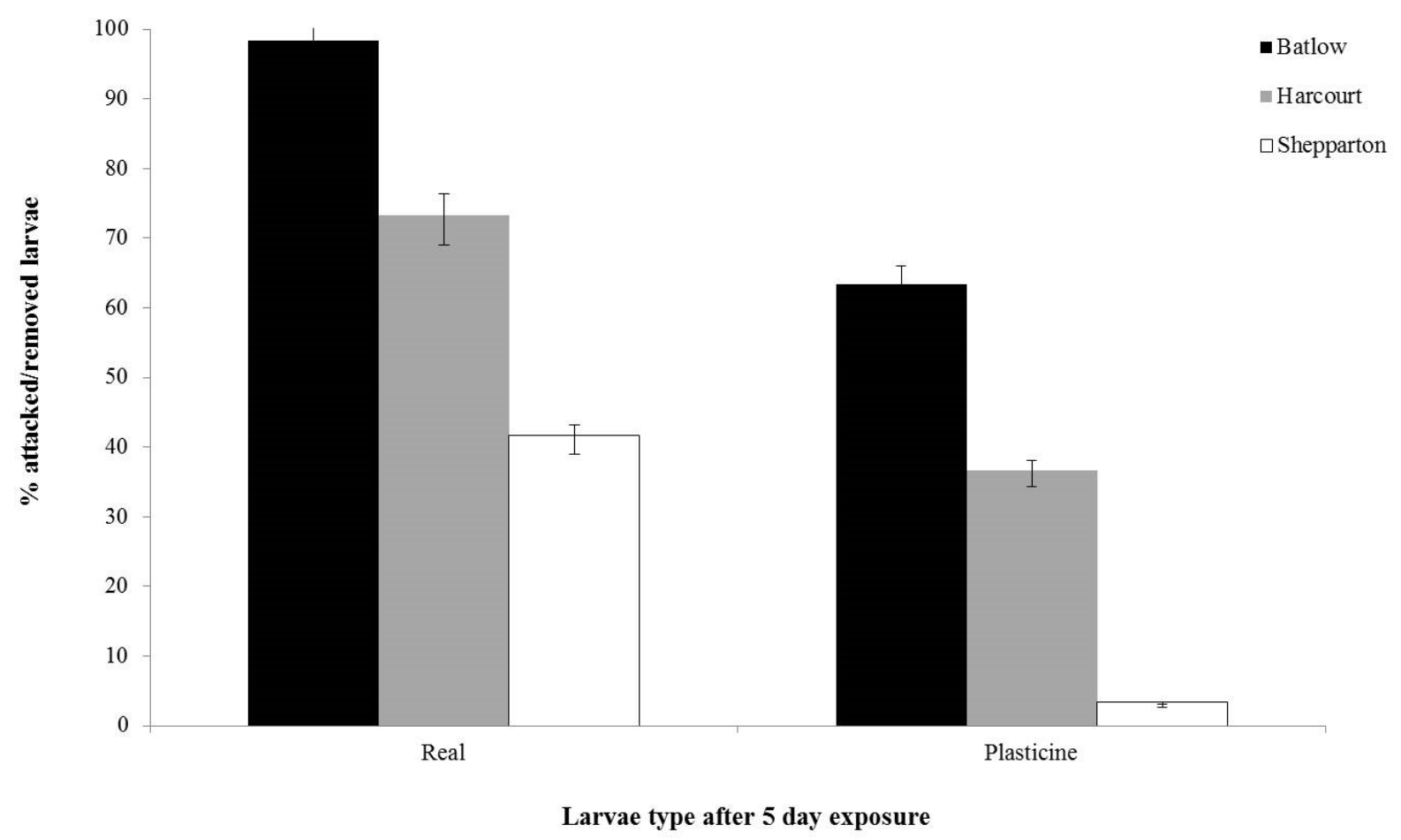

630

631 Figure 4. Least squares means of the number of real and plasticine larvae attacked/removed from each

632 region. Error bars show 95\% confidence intervals.

633

634 


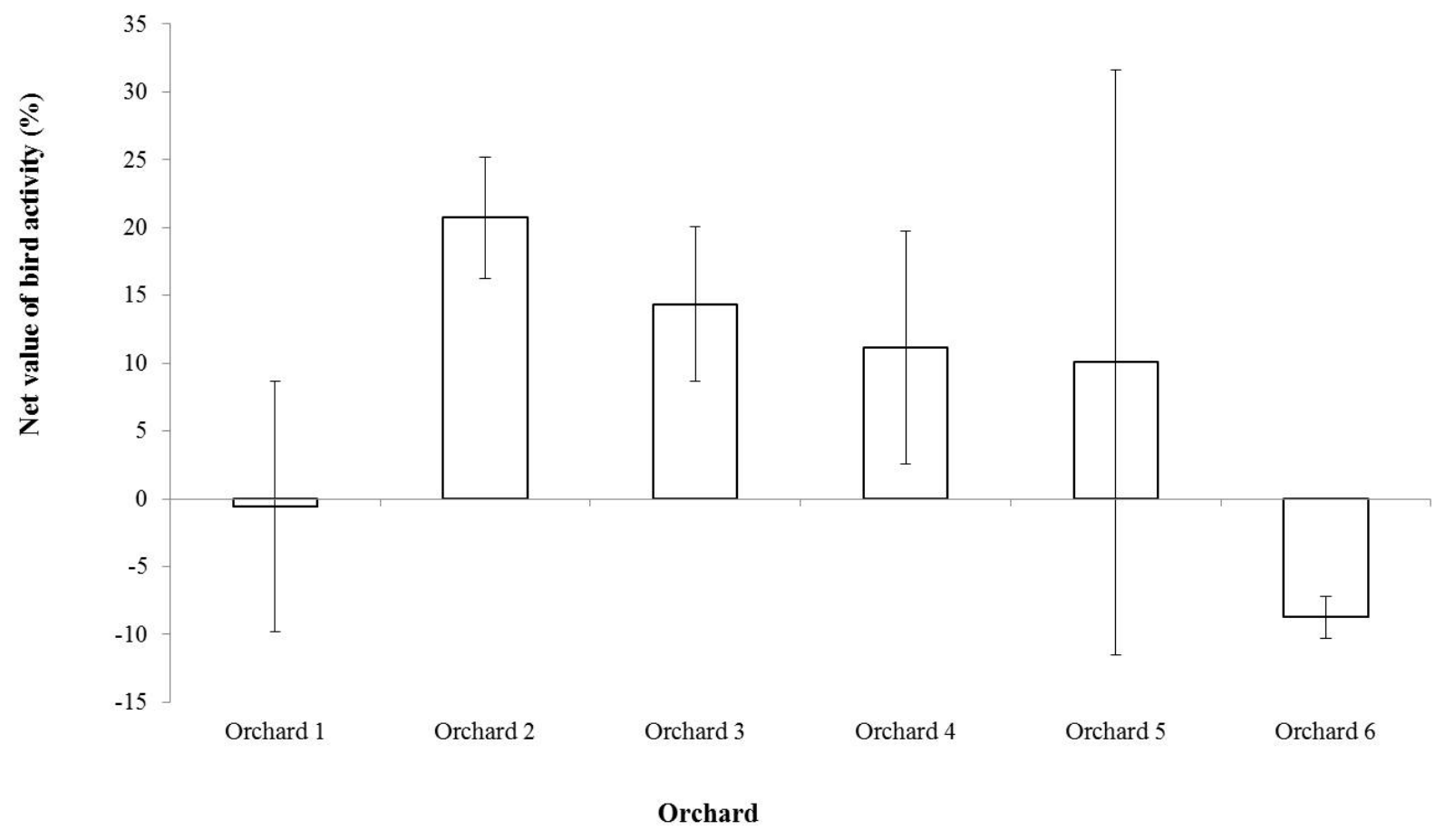

635

636 Figure 5. Net value of bird activity in apple orchards when considering a cost-benefit trade-off (i.e. reduction

637 in insect damaged fruit minus amount of bird damaged fruit). Orchards are listed 1-6 from lowest intensity

638 management to highest intensity. Error bars show 95\% confidence intervals.

639

640

641

642

643

644

645

646 